\title{
A CIDADE COMO CONSTRUÇÃO MODERNA: UM ENSAIO A RESPEITO DE SUA RELAÇÃO COM A SAÚDE E AS "QUALIDADES DE VIDA".
}

\author{
Rubens de Camargo Ferreira Adorno*
}

RESUMO: Este artigo pretende tratar o problema do urbano como condição e modo de vida da cidade relacionando algumas perspectivas de sua discussão com o agravamento das condiçőes sanitárias e as várias conseqüências para a sobrevivência de indivíduos e grupos. Procura situar este problema no chamado "capitalismo flexivel", a fragmentação e a retórica da "qualidade" no cenário da vida cotidiana contemporânea.

PALAVRAS-CHAVE: modernidade reflexiva, qualidade de vida, sociabilidade, circuitos urbanos, saúde pública

* Sociólogo, Doutor em Saúde Pública. Professor Associado do Departamento de Saúde Materno Infantil. Faculdade de Saúde Pública da Universidade de São Paulo. Av. Dr. Arnaldo, 715 - $2^{\circ}$ andar sala 218 São Paulo - SP CEP 01246904. Fone (11) 881-2451 Fax (11) 853-0240 E-mail radomo(d) usp.br 
O tema da "dinâmica urbana" nos remete, num primeiro momento, à cidade como território, que tem sua história citada desde a antigüidade evocada como cenário de tragédias, espetáculos épicos, construções monumentais.

Quando falamos da relação da cidade com a saúde, falamos do nascimento da cidade moderna, a partir do século XVIII, que passou a ser um campo e território de intervenção sobre as possibilidades humanas: das ameaças sanitárias das epidemias e das doenças, de revoltas sociais, do pânico; tudo isso necessitava ser superado para que tudo pudesse fluir, como deveria fluir a economia mercantil.

O século XIX vai focalizar o tema do urbano, que vai deixando de ser o território de intervenções e de práticas para tornar-se o cenário em que se observa o surgimento de um "modo de vida": de um lado o fascínio pela multiplicidade, pelo ritmo, pela aglomeração; de outro, o barulho, a produção, as precárias condições de vida, os pobres e as classes trabalhadoras que são vistos como o lado ameaçador e perigoso da ordem, que devem ser tomados como o objeto de intervenção das milicias do Estado, da higiene, do desalojamento. O modo de vida urbano durante este século será também a constituição de um cenário em que as modas, os estilos aparecem, as idéias são divulgadas e discutidas através da imprensa e dos diversos círculos, as revoltas e movimentos passam a ocupar as ruas para mostrarem-se, exigirem e negociarem direitos. O urbano é um território de hierarquias, diferenças e desigualdades, mas é também o campo de novas possibilidades, de conflito e negociação, de conquistas e de invenção de estilos e novas perspectivas de vida urbana. A qualidade da vida urbana é identificada à sua capacidade de mudança, de superação.

A passagem do século $X X$ vai representar a generalização da vida urbana não apenas como um processo demográfico de crescimento das cidades, mas também como um modo de vida que passa a se expandir para todos os territórios do globo envolvendo, ao mesmo tempo, todas essas tradições da história da cidade moderna e intensificando esse modo de vida, apontando para problemas clássicos que reaparecem com uma nova qualidade.

O movimento de ordem e mudança parece se fragmentar em múltiplos territórios, expectativas, a intervenção clássica que situou a partir da cidade a hegemonia dos Estados Nacionais e de suas instituições de intervenção e legitimação aparecem como limitados e restritos para dar conta dos problemas urbanos, os modelos de planejamento urbano, 
econômico, sanitário se vem não só como insuficientes mas inadequados em relação às demandas que se apresentam.

Discorrer sobre o problema da cidade e de suas implicações para a sobrevivência das pessoas é navegar, portanto, neste território bastante amplo que limitamos aqui como a história moderna. Podemos apresentar mais alguns "flashes" dessa questão visitando alguns autores que nos permitiram realizar esta introdução, situando o tema da cidade e, portanto, do urbano como organização do espaço e como modo de vida. Deixamos claro que vamos entrar em uma discussão complexa e, por isso, vamos aqui nos limitar a um ensaio a respeito de temas e tratamentos da cidade e, por extensão, do modo de vida urbana que ela inaugura nesse cenário denominado de modernidade.

A primeira e clássica referência é FOUCAULT (1979), que nas histórias da medicina, da psicologia, etc... vai interpretar o sentido das instituições modernas e nos dar a grande contribuição de mostrar que as intervenções são feitas a partir daquilo que se estabelece como visível, este visível envolveu nesta história o poder do "saber".

Para FOUCAULT, a cidade, as instituições nascem como o projeto de disciplinar o espaço e as pessoas, o esquadrinhamento e a internação. Sua linha de pensamento é um ponto crítico de apoio à autonomia dos pacientes e, portanto, dos direitos dos indivíduos.

\section{A INTERVENÇÃO SANITÁRIA COMO DISCIPLINA DO CORPO DA CIDADE}

Partindo da reconstrução do modelo da cidade francesa do século XVIII que, como outras cidades da época, se constituia em um aglomerado de poderes e de zonas de diferentes jurisdições, rivalidades e de territórios emaranhados FOUCAULT (1979) descreve como a intervenção sanitária serviu de instrumento para unificação do poder e implantação de uma ordem à cidade.

Essa intervenção representa também um marco de referência da cidade moderna, como território de hegemonia econômica, território de conflito político. A cidade, por se constituir em uma aglomeração, representava uma ameaça aos costumes e à saúde.

No imaginário, as doenças e os costumes traduzem-se em um mesmo patamar de ameaça das cidades...."todas as vezes que os homens se reúnem, seus costumes se alteram; todas as vezes que se reúnem em lugares fechados, se alteram seus costumes 
e a sua saúde. Nasce o que chamarei de medo urbano, medo da cidade, angústia diante da cidade que vai se caracterizar por vários elementos: medo das oficinas e fábricas, ...do amontoamento da população, das casas altas demais, dos cemitérios que se tornam cada vez mais numerosos e invadem pouco a pouco as cidades, dos esgotos, das caves sobre as quais estão se construindo as casas que estão em perigo de desmoronar...." (FOUCAULT, 1979, p: 86).

Um outro ponto gerador desse pânico e medo da cidade dizia respeito às questões políticas da cidade no século XVIII. As distintas ordens e corporações de ofício representavam territórios diferentes no tecido urbano, mas não necessariamente rivais. As tensões políticas entre ricos e pobres, proprietários e assalariados representaram um outro tipo de conflito, que se expressam como agitações e levantes - definindo aqui um limite histórico, que define também a oposição entre campo e a cidade, as revoltas camponesas são a ameaça à ordem do século XVII para trás, tornando-se as revoltas urbanas o centro das atenções durante o decorrer do século XVIII.

Para FOUCAULT (1979), esta junção da observação do desenvolvimento da cidade, do imaginário sobre o pânico das doenças, assim como das revoltas, levou a estratégias que passarão a fazer parte das instituições modernas, que nascem como instituições urbanas: o esquadrinhamento para detectar focos e intervir sobre eles toma - lugar da "quarentena", que era a estratégia de combate às epidemias herdada da idade média e que paralisava o corpo social dominado pelo pânico e pelos maus humores; e o internamento toma o lugar da exclusão. Passam a ser modos de intervenção. Analisar os lugares de acúmulo e amontoamento de tudo que no espaço urbano pode provocar doença, lugares de formação e difusão de fenômenos epidêmicos ou endêmicos, controlar a circulação, da água e do ar, passam a operar novos modos de intervenção, que se alicerçam no poder do Estado, que tomam os lugares, o movimento da cidade e buscam regular sua circulação como a de um corpo.

Como historiador da Saúde Pública ROSEN (1994) focaliza esse processo "clássico" da urbanização a partir da Revolução Industrial na Inglaterra, no qual o crescimento das cidades, a situação de pobreza da classe trabalhadora, que passa a ser representada a partir da descrição de suas habitações, o quadro crítico das cidades da Europa no século XIX, muitas vezes revisitado nas cidades brasileiras da dé - - ta de 70. A insalubridade é representada pela falta de saneamento e pelas condições da moradia, aglomeração e ausência de higiene pública e sua relação com as epidemias. 
As classes abastadas procuram se afastar dos locais insalubres, onde residia 0 proletariado. A segregação espacial passaria, então, a representar a defesa da "qualidade de vida" desses grupos sociais. Os modelos de segregação espacial representam, desde então, a inscrição da desigualdade social no território e na história da cidade. Foi a cidade e o desenvolvimento urbano, portanto, que também contribuiram para esta visibilidade, a de passar a ter a diferença e a desigualdade social como um problema a ser resolvido.

Além das coisas e lugares as pessoas são outro campo de intervenção; os pobres, doentes, desocupados e sublevados passam a ser tomados então como objetos da sanidade urbana e da ordem pública, para tais são criadas as instituições de internação. Dessa forma se completa a institucionalização sanitária da cidade moderna.

A Saúde Pública, a partir do século XVIII (FOUCAULT, 1979; ROSEN, 1994), tal como se traduziu como campo de observação, pesquisa e intervenção, é uma prática urbana, que surge da observação das cidades, considerando-se como um modelo de conhecimento e de intervenção que teve como instrumento o Estado e a sua relação de poder com as populações.

A partir de então a cidade, como expressão mais nítida e privilegiada da forma de vida urbana, tem sido apontada, ao menos no domínio do tempo do que tem se convencionado chamar de "modernidade", como o território da intervenção em saúde e da constituição da saúde na esfera pública.

Destaca-se que a cada momento, apesar do estilo de vida urbana extravasar os limites das cidades, a "Saúde Pública" tem buscado situar e ampliar seu campo de problemas a partir da observação da vida nas cidades.

Uma das características centrais da modernidade é seu elemento reflexivo (GIDDENS 1994; BECK, 1997), ou o fato de ser produto da intervenção que exerce sobre si mesma; desse modo, ao se interpretar a intervenção sanitária sobre a cidade não se deve pensá-la como cumulativa, mas reflexiva. Dessa maneira vai se incorporando ao próprio modo de vida urbano a tradição das intervenções sanitárias sobre a cidade, assim como seu imaginário. A intervenção nova guardará como fato, e não apenas como memória, as intervenções passadas, pelo menos ao se pensar na permanência das instituições modernas. Estas instituições estão sendo colocadas em questão na 
contemporaneidade, o que não esgota o sentido de sua ação: pode não se tratar desse ou daquele estilo de intervenção sanitária, mas a intervenção da saúde continuará a fazer parte da cidade. A tradição, nesse sentido, não significa continuidade, mas incorporação de idéias, crenças, conhecimentos anteriores a cada nova situação de mudança de ação.

\section{A CIDADE COMO EXPERIÊNCIA, O URBANO COMO FORMA DE VIDA}

Precisamos lançar mão de um outro olhar, de uma outra sensibilidade para "completar" essa herança das leituras de FOUCAULT (1979), para caracterizar a vida urbana; um olhar em uma outra direção, que toma como "visível" o cotidiano; e é nessa experiência de vida urbana que se vislumbram táticas de superação, sobrevivência, negociação e invenção de modos de vida que escapam e que se distanciam da idéia das instituições disciplinares, que situam mesmo o desenvolvimento da vida urbana na cidade além de uma perspectiva de intervenção sobre os individuos e as coisas, e como um campo de possibilidades para criarem novas perspectivas de vida.

SIMMEL (1974) e posteriormente a Escola de Chicago vão constituir um corpo teórico a respeito da cidade e da vida urbana como modo de vida. No que concerne à busca de entendimento da vida urbana será sem dúvida SIMMEL que situa o tema da especialização dos indivíduos como forma de resistência à homogeneização. Este raciocínio está na origem do entendimento da cidade como um entrecruzar de circuitos e de modos de vida. A qualidade de vida, mais do que uma expressão material da estrutura da cidade, implica na possibilidade desta realização, o indivíduo que procura seus circuitos de identidade e constrói sua individualidade na especialização de gostos, identidades e circuitos.

Será no século XIX que esta "visibilidade", para usar um conceito de FOUCAULT, que a cidade se constituirá como território do consumo do comportamento, da higiene, dos cuidados com o corpo guardando, então, uma estreita relação entre estas e a constituição moral, a moral das elites e das classes dominantes colocadas como modelo e miragem, como exemplo a ser seguido. Essa versão deve permitir, entretanto, uma relativização, pois, é também a partir da percepção da vida urbana do século XIX que a condição da multiplicidade, do anonimato, da especialização de estilos e de territórios demonstrarão, ser de fato, mais complexa a relação e os limites da ação das instituıções e dos modelos disciplinares, do que nos mostrou FOUCAULT. O Domínio do diverso, 
das práticas do dia a dia, de inúmeras táticas cotidianas (DE CERTEAU, 1994), diversificam os campos e contrastam a recepção dos modelos dominantes; antes, passam a assinalar que a cidade território de instituição da vida urbana propicia na cena pública a rejeição, inclusive dos modos de vida dominantes.

Na abordagem de SIMMEL (1976) e na apreensão da cidade moderna realizada por BENJAMIN (1994), a partir da literatura sobre a cidade do século XIX, o tema da multiplicidade e da presença do urbano como diversidade e movimento já se encontrava presente. A cidade e a vida urbana são vistas como elementos contraditórios, não na sua superfície ou no seu território, como farão as análises que pensarão a cidade capitalista como resultado das contradições desse modo de produção, mas como uma contradição entre o olhar que admira e o olhar que se espanta. Assim, a "massa", o anônimato amedrontam mas também possibilitam admiração: do olhar sem escutar, do perigo, mas também da sedução de se misturar a ela, de encontrar o fascínio, o erótico, o prazer, a escolha.

O urbano ou o ritmo da metrópole é apontado por SIMMEL (1976) como uma mudança de qualidade nas esferas de vida. A relação da cidade como campo de realização da vida monetária, do capitalismo, é situada como uma órbita de organização do tempo que impõe sua dinâmica externa aos homens e vai coordenar seu ritmo e seu movimento. Essa dinâmica levará à cisão entre o "emocional" e o "intelectual" e propiciará o desenvolvimento de um tipo especifico de individualidade, voltada para o ritmo monetário. Esta individualidade torna o homem "indiferente " ("blasé"), assim como o excesso de estímulos propicia essa sensação. Por outro lado, essa indiferenciação leva à procura pela especialização da individualidade. A resistência a essa indiferença se reverte no esforço de construir um território para a individualidade.

O urbano, como um território caracterizado pela diversidade, se coloca como uma perspectiva de olhar para a cidade não apenas através de seu crescimento demográfico, de seu "caos", ou de sua condição degradada. A "Escola de Chicago" falará da "ecologia urbana" buscando compreender no território da cidade a marca das diferentes tradições culturais que passam a marcar sua origem, e também dos diferentes estilos de vida que se criam e se apresentam neste espaço. Essa condição percebida da vida urbana possibilitará vislumbrar, nesse campo, o problema da diversidade, além da percepção da desigualdade. 
O tema da "qualidade de vida" da cidade não pode ser colocado apenas na dimensão da intervenção sobre o espaço determinada pela diferença, ou pela separação das elites, ou pela melhoria das condições dos "pobres", mas passa também pelas diferentes expectativas dos diferentes grupos da cidade.

Como dissemos desde o começo, impossivel esgotar as apreensões sobre a vida urbana no século $X X$. Devemos destacar que o signo da diferença marcará a análise estrutural da cidade como produto da acumulação capitalista. Outras análises tomarão como fulcro a imagem da cidade industrial. Nestas perspectivas, as demandas urbanas foram tratadas como determinadas pelas diferenças na estrutura da cidade, motivadas pela desigualdade da distribuição e pelas contradições da acumulação capitalista. As melhorias das condições de vida e dos equipamentos urbanos como valorização do capital. Essas análises sofrerão críticas pelo seu raciocínio instrumental e pela imagem instrumental que passaram a fazer da ação dos indivíduos, das classes e dos distintos grupos urbanos.

O foco sobre a vida urbana e a sociedade contemporânea vai recuperar o caminho de análise de SIMMEL (1976), formulado no inicio deste século, e irá acrescentar novas perspectivas e qualidades ao observar na vida cotidiana, os movimentos que passam pela intimidade e a sua representação pública, pelo individual e coletivo, pelas questões da desigualdade, da diferença e do gênero. Além disso a perspectiva de direito, democracia, busca de autonomia, juntamente com a reivindicação da melhoria das condições de vida, vão apontar para a discussão das saidas para os problemas da cidade, juntamente com a saída para os problemas da "sociedade global" do final do século.

O tema da globalização, da generalização do modo de vida urbano (ROBIN, 1997; HARVEY, 1995) veio a se tronar um dos tópicos privilegiados para o pano de fundo das análises que se fazem a respeito da contemporaneidade. As teorias de explicação da "alta modernidade", ou da "pós modernidade", passaram a dar ênfase na condição das cidades como espetáculo, como polos de serviço, ou como propulsoras de grandes empreendimentos culturais. A cultura, o cenário, o marketing, a revitalização de espaços fazem parte da imagem atual das cidades. O cultural tornou-se um grande empreeendimento ou um jargão comum a todos (ARANTES, 1996).

O "capitalismo flexível" (HARVEY, 1995), o "capitalismo tardio" (SENNETT, 1999), como tem sido caracterizado, vem assinalando a fragmentação das antigas esferas e 
instituições sociais. Por um lado, há a referência à crise de uma forma de produzir mercadorias - o "fordismo" - e as instituições a ela ligadas, uma série de métodos e novas tecnologias passam a desmontar as esferas de produção que descortinam em outra ponta a desestruturação dos sistemas formais e estáveis de trabalho.

LEVY (1997) assinala a tendência à fragmentação e a uma maior autonomização dos espaços na cidade como produto já da crise das formas de trabalho estável. A informalidade, a busca de atividades de serviço em zonas muito distante dos locais de moradia vão propiciando um novo perfil à cidade. Por outro lado, o trânsito, o aumento da circulação é acelerado pelo aumento do fluxo de entrega e montagem de mercadorias, assim como os fluxos entre as cidades entre regiões e entre países.

Um outro lado dessa desregulamentação aparece nas "economias paralelas", como a "economia da droga", que se articula internacionalmente e que passa a ocupar as regiões degradadas. Porque menos freqüentadas e "escondidas" dos serviços da cidade. A economia paralela passa a ser forma de ocupação para grandes parcelas da população dos jovens pobres.

O tema da violência e da insegurança passa, nas últimas décadas do século, a se identificar com o tema da cidade, a se identificar com determinados territórios. Se na perspectiva dos teóricos marxistas a respeito da cidade esta é fruto das relações sociais, e mais fortemente das relações sociais de produção, a imagem contemporânea seria traduzida pelas "não relações" (WIEVIORKA, 1999), pela negação, pelos grupos que se excluem, pelos territórios que se rivalizam.

A cidade contemporânea aparece como espaço das distintas sociabilidades, com a presença de espaços que se comportam como "ghetos", em que áreas se degradam, outras são produzidas como espetáculo e propiciam a criação de grupos na órbita da sensibilidade cultural, consumo, segmento geográfico, gênero, opção sexual.

Os espaços da cidade são interligados e adquirem uso especializado não apenas do ponto de vista da lógica da economia flexível - comércio, serviço, plantas de planejamento e montagem - mas são colonizados e implementados pelos diferentes grupos, que traçam seus circuitos, de acordo com estilo de vida, gostos, segmentos de consumo (MAGNANI, 1996). A presença das segmentações de público e dos intermediários culturais (FEASTHERSTONE, 1995) passam a produzir demandas, 
produtos culturais e passam a fazer parte da produção cultural, parte da economia das cidades que se especializa. Assim como as "comunidades de grupo", a especialização pelos distintos grupos de idade se fazem presentes na segmentação e da demanda do espaço urbano.

Destacamos que neste quadro amalgamático se dispõem e sobrevivem as "tradições" da vida urbana na história moderna. Assim, as perspectivas de superação dos problemas: opressão, desigualdade, inscritas no território da cidade como um campo de conflito, representado no início do século XIX pelo conflito entre a revolta dos pobres, então considerados "as classes perigosas"; posteriormente aparecendo na cena pública como classe trabalhadora em conflito com a burguesia, constitui outra tradição dessa história da cidade, que no século $X X$ torna-se cenário para as múltiplas reivindicações $e$ projetos de autonomia, inserindo-se nas "gramáticas" ou "políticas da vida". Esfera pública, esfera privada, intimidade, gênero, são questões da vida contemporânea.

A relação entre as diferentes formas de sociabilidade, espaços excluidos e saúde, articula-se, por um lado, ao que se chamou "formas de vida ameaçadas" (ADORNO, 1996,1997); e, por outro, ao reconhecimento de novos sujeitos, novas demandas e novos direitos, como o caso dos grupos de idade e da relação entre saúde e uso da tecnologia dos meios diagnósticos. A saúde, a qualidade de vida tornam-se preceitos que por sua vez incorporam novos segmentos de consumo. A cidade contemporânea fala da doença através da metáfora das "dietas" do corpo, estas por sua vez demandam novos produtos e tecnologias terapêuticas e diagnósticas.

O quadro cultural acaba sendo chamado para se incorporar a este campo da intervenção da saúde. Esta além de necessitar situar os saldos não resolvidos da montagem da cidade: ausência de saneamento básico, disponibilidade de serviços; esta passa a ser caracterizada por um enorme campo reflexivo, da reprodução artificial e das conseqüências da história de sua própria ação e da ação reflexiva da "modernidade" sobre a própria sociedade.

Nesse quadro situa-se também o marketing da qualidade que, por sua vez, passa ao largo de espaços deteriorados, zonas excluidas ou dominadas pelas economias paralelas, e portanto, identificadas como zonas violentas, grupos que habitam praças e ruas, etc. cenas e situações existentes hoje nas "cidades globais", independente de sua posição no hemisfério norte ou sul, ou de sua longitude" (ADORNO, 1997). 
As periferias, as cidades planejadas e bairros planejados, os "squats" que aparecem nas regiões centrais deterioradas fazem parte do cenário das cidades contemporâneas, da mesma forma que os espaços espetáculo, as zonas produzidas para serem vistas e seu marketing turístico cultural. Também o ritmo de vida, a insegurança no emprego, o sentimento de insegurança em relação às ruas e ao trânsito podem coexistir com o slogan da "qualidade de vida". Qualidade de vida pode ser vista, assim, como uma utopia em relação ao problema da desigualdade e da diferença existentes na cidade, ou pode ser concebida como os espaços protegidos para as elites que nela vivem. Este segundo aspecto pode ser entendido através da criação de "espaços artificias" reais e virtuais: tratam-se dos espaços segregados, do uso de veículos herméticamente fechados que os interligam - condomínios fechados, academias, prédios inteligentes, shopping centers, clínicas; mas também espaços interligados através das viagens internacionais etc. Assim, grande parte da qualidade é identificada com a construção de espaços protegidos.

Assim como a referência à modernidade representa um maior risco (GIDDENS, 1996), esse risco que não é apenas o da violência, mas da segurança íntima, das relações que são "negociadas", da instabilidade e competição no emprego, da perda de controle sobre o espaço e o tempo, da distância das relações e papéis das gerações, dos membros adultos da familia (SENNET, 1999).

As perspectivas de ação sobre a cidade também devem ser, portanto, pensadas em planos diversos. A mobilização local como um novo tipo de "comunitarismo" vem sendo apontado como possibilidade real e tática cotidiana, tendo como base as novas condições das "economias locais" da cidade que tem levado a um empreendimento a partir de atividades informais para gerir a sobrevivência não só das pessoas, mas de sua continuidade no local de moradia, vizinhança e de auto ajuda, ao lado de políticas de descentralização de poder e de mobilização cultural.

Uma outra condição é apontada pela visibilidade dada aos problemas pessoais, que se representam a partir da grande reflexividade das "dietas de saúde", das prevenções das compulsões. Os grupos de auto ajuda e as redes de solidariedade que se formam em torno de questões como as novas doenças crônicas e as compulsões pessoais.

Nesses enfoques sobre a cidade algumas tradições já apontadas como a relação entre o indivíduo e a massa (SIMMEL, 1974; BENJAMIN, 1980) serão revisitados, ou 
reconstruídos, traduzindo-se no entanto na cidade como um campo de múltiplos circuitos, assim, portanto, como a generalização do urbano como modo de vida.

O planejamento, as políticas públicas se vêem diante de uma "fragmentação" das populações e do território. Ao surgimento dos movimentos que se articulam perante as "políticas da vida", seu percurso necessitará seguir também o percurso dos diversos e vários planos de organização, decifrar um léxico que entrecorta cada vez mais público e privado, diferente e desigual.

Qualidades de vida ou qualidades das vidas? Como podemos pensar essa condição de forma a empreender uma construção envolvendo a organização do espaço, a disponibilidade de recursos e a busca de um modo de vida. Revisitar algumas das teorias que relacionaram a cidade, o modo de vida, levam a compreender que superadas as grandes ameaças à vida, representadas pelas carências de abastecimento e disponibilidade de alimentos, a existência de saneamento e debeladas as epidemias, e mesmo considerando-se essas adversidades, as condições da vida na cidade apresentam-se como condições plásticas. Assim, mesmo em condições adversas como a instabilidade econômica, de emprego, o ritmo e condições "stressantes", pobreza nunca se falou tanto de "qualidade de vida". Será, portanto ainda, a esperança dos dias melhores um motor para a utopia do próximo século, apesar da permanência e multiplicação das diferentes qualidades das vidas que a cidade propicia hoje?

\section{REFERÊNCIAS BIBLIOGRÁFICAS}

ADORNO, R.C.F. Qualidade de vida e formas de vida ameaçadas: a saúde e o cenário contemporâneo. São Paulo, 1997. [Texto apresentado para concurso de livre docência na Faculdade de Saúde Pública da USP].

ADORNO, R.C.F. Os imponderáveis conceitos dos vulneráveis cidadãos: trajetórias de crianças e jovens das classes populares. In: LEANER, J. (coord.) Cidadania: verso e reverso. São Paulo, Imprensa Oficial do Estado de São Paulo, 1997/1998.

ARANTES, O . Cultura da cidade: animação sem frase. Rev. Patrimônio Hist. Art. Nac. 24:229-42, 1996.

BECK, U. Modernização reflexiva: politica, tradição e estética na ordem social moderna. São Paulo, Editora da UNESP, 1997. 
BENJAMIN, W. Obras escolhidas III: Charles Baudelaire um lírico no auge do capitalismo. São Paulo, Brasiliense, 1994.

DE CERTEAU, M. A invenção do cotidiano: artes de fazer. Petrópolis, Vozes, 1994.

DURHAM, E. A caminho da cidade. São Paulo, Editora Perspectiva, 1984.

FEATHERSTONE, M. Cultura de consumo e pós-modernismo. São Paulo, Studio Nobel, 1995.

FOUCAULT, M. O nascimento da medicina social In: FOUCAULT, M. Microfísica do poder. Rio de Janeiro, Graal, 1979. p. 79-98.

GIDDENS, A. As conseqüências da modernidade. São Paulo, Editora da UNESP, 1991.

GUIDUUCCI, R. A cidade dos cidadãos. São Paulo, Brasiliense, 1980.

HARVEY, D. A condição pós-moderna. São Paulo, Loyola,1995.

LEVY, E. Democracia nas cidades globais: um estudo sobre Londres e São Paulo. São Paulo, Studio Nobel, 1997.

MAGNANI, J.G.C. Quando o campo é a cidade. In: MAGNANI, J.G.C.; TORRES, L.L., org. Na metrópole: textos de antropologia urbana. São Paulo, Edusp/Fapesp, 1996. p.12-53.

ROBIN, C. Espaces et aires transactionnelles In: YOUNĖS, C. \& MANCEMATIN, M. Lieux contemporains. Paris, Descartes \& Cie, 1997. p. 135-76.

SENNETT, R. A corrosão do caráter: conseqüências pessoais do trabalho no novo capitalismo. Rio de Janeiro, Record, 1999.

SIMMEL, G. A metrópole e a vida mental. In: VELHO, O. G., org. O fenômeno urbano. Rio de Janeiro, Zahar Editores, 1976. p. 11-25.

WIEVIORKA, M. La violence en France. Paris, Seuil, 1999. 
SUMMARY: The present article aims at depicting the urban issue as mode and condition of life in the city. It relates a few perspectives of the discussion to the worsening of sanitary conditions and the several consequences for the survival of individuals and groups. It aims at placing the problem within "flexible capitalism", fragmentation and rhethoric of "quality" in the scenario of contemporaneous daily life.

KEY WORDS: reflexive modernity, quality of life, public health 